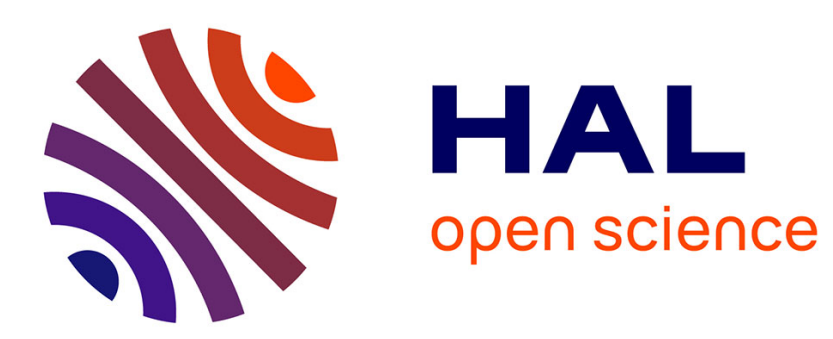

\title{
On French listeners' ability to use stress during spoken word processing
}

\author{
Amandine Michelas, Nuria Esteve-Gibert, Sophie Dufour
}

\section{To cite this version:}

Amandine Michelas, Nuria Esteve-Gibert, Sophie Dufour. On French listeners' ability to use stress during spoken word processing. Journal of Cognitive Psychology, 2018, 30 (2), pp.198 - 206. 10.1080/20445911.2017.1394862 . hal-01724606

\section{HAL Id: hal-01724606 https://hal.science/hal-01724606}

Submitted on 12 Apr 2019

HAL is a multi-disciplinary open access archive for the deposit and dissemination of scientific research documents, whether they are published or not. The documents may come from teaching and research institutions in France or abroad, or from public or private research centers.
L'archive ouverte pluridisciplinaire HAL, est destinée au dépôt et à la diffusion de documents scientifiques de niveau recherche, publiés ou non, émanant des établissements d'enseignement et de recherche français ou étrangers, des laboratoires publics ou privés. 


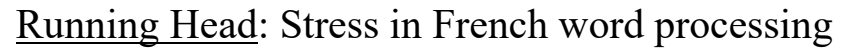

On French listeners' ability to use stress during spoken word processing

Amandine Michelas, Núria Esteve-Gibert and Sophie Dufour

Aix-Marseille Université, CNRS, LPL, UMR 7309, 13100 Aix-en-Provence, France 
Abstract: Previous studies have suggested that French listeners experience difficulties when they have to discriminate between words that differ in stress. A limitation is that these studies used stress patterns that do not respect the rules of stress placement in French. In this study, three stress patterns were tested on bisyllabic words (1) the legal stress pattern in French, namely words that were unstressed compared to words that bore primary stress on their last syllable (/зуьі/-/зу'кі/), (2) an illegal stress location pattern, namely words that bore primary stress on their first syllable compared to words that bore primary stress on their last syllable (/'зуві/-/зу'ві/) and (3) an illegal pattern that involves an unstressed word, namely words that were unstressed compared to words that bore primary stress on their first syllable (/зивi//'zиьi/). In an ABX task, participants heard three items produced by three different speakers and had to indicate whether $\mathrm{X}$ was identical to A or B. The stimuli A and B varied in stress

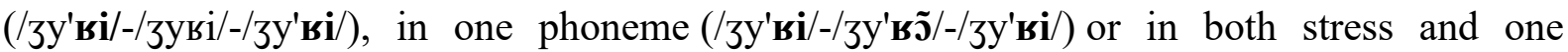
phoneme (/зу'ві/-/зуво̃/-/зу'кі/). The results showed that French listeners are fully able to discriminate between two words differing in stress provided that the stress pattern included an unstressed word. More importantly, they suggest that the French listeners' difficulties mainly reside in locating stress within words.

Key-words: Speech perception; word discrimination; French prosody; primary stress 
Word recognition from the speech signal is a key aspect of spoken language comprehension. To correctly identify spoken words, one of the first tasks for listeners is to extract both segmental and suprasegmental information from the speech signal. The product of this analysis is then projected onto the phonological representations of words stored in the mental lexicon. The current study focuses on this first step of spoken word recognition, and examines the relative contribution of both segmental and suprasegmental information in the discrimination of French words.

Numerous studies conducted in several languages have already been done to examine the role of segmental and suprasegmental information such as stress ${ }^{1}$ in word perception (e.g., McQueen, Norris \& Cutler, 1994 for English; Cutler \& Van Donselaar, 2001 for Dutch; SotoFaraco, Sebastian-Galles \& Cutler, 2001 for Spanish; Sulpizio \& McQueen, 2012 for Italian; Lee, 2000 for Mandarin Chinese; Cutler \& Otake, 1999 for Japanese). For example, in a cross-modal priming experiment, Soto-Faraco et al. (2001) presented to Spanish listeners sentences ending with word fragments, and asked them to perform a lexical decision task on letter strings (i.e. targets) presented at fragment offset. Fragment primes either fully matched (pa'pi) or mismatched either in stress ('papi) or in one phoneme (pa'ti) the auditory form of the initial portion of target words (papi'lla) ${ }^{2}$. In comparison to a control condition in which there was no overlap between the fragment primes and the target words, the authors reported that fully matching primes facilitated target word processing, while mismatching primes both in stress and phoneme inhibited target word processing. Such results suggest that in Spanish suprasegmental and segmental information similarly influence spoken word perception. 
The fact that suprasegmental information contributes as equally as segmental information to word discrimination is not so surprising in languages such as Spanish where stress location is lexically contrastive (e.g., /'bebe/ "s/he drinks" vs. /be'be/ "baby"). But what about languages such as French where it is not possible to find minimal pairs of words differing in stress location?

In French, stress always affects the last syllable of a melodic group, which is a larger unit than the word". As a result, the same word receives stress ([un petit 'CHOU]) "a little cabbage" or not ([un CHOU 'bleu]) "a blue cabbage" depending on its position within a melodic group. As such, several studies indicated that French listeners use stress to segment speech into words, and in particular to locate word onset/offset in continuous speech (Rietveld, 1980; Bannel \& Bacri, 1994; Christophe, Peperkamp, Pallier, Block \& Mehler, 2004; Spinelli, Welby \& Schaegis, 2007; Spinelli, Grimault, Meunier \& Welby, 2010). For example, Christophe et al. (2004) have shown that stress helps French listeners to resolve competition between overlapping lexical candidates. The authors asked participants to detect a target word (e.g., CHAT "cat") in sentences like [Le CHAT grin'cheux] "the grumpy cat" in which only the word "grincheux" is stressed on its last syllable or in sentences like [Le $\boldsymbol{C H} \boldsymbol{A T}$ ] [grim'pait] "the cat climbed up" in which both the words "chat" and "grimpait" are stressed. They found slower detection times in [Le CHAT grin'cheux] than in [Le CHAT] [grim'pait]. The slower detection of CHAT in [Le CHAT grin'cheux] has been interpreted as resulting from competition between CHAT and its competitor CHAGRIN "sadness". In this case, since there is no stress on CHAT to indicate its end, the word CHAGRIN remains active and competes with the word CHAT. 
Although it clearly appears that French listeners can use stress to resolve lexical ambiguities, the story regarding stress processing in French is rendered more complex than it seems by the fact that stress can also be difficult to perceive by French listeners. In their study, Dupoux and collaborators (Dupoux, Pallier, Sebastian \& Mehlher, 1997) compared French and Spanish listeners in the processing of stress. In an ABX task, in which A, B and X were spoken by three different speakers, and in which participants judged whether $\mathrm{X}$ was identical to $\mathrm{A}$ or $\mathrm{B}$, the authors showed that French listeners had more difficulties than Spanish listeners in discriminating between two nonsense words that differed only in stress position ('fidape, fi'dape,). In addition, French listeners, unlike Spanish listeners, performed worse when the stimuli differed in stress ('fidape, fi'dape) than in phoneme ('fidape, 'lidape). It was only when the stimuli were produced by a single speaker that French listeners performed equally well on stress ('fidape vs. fi'dape) and phoneme ('fidape vs. 'lidape) contrasts. The authors concluded that stress is likely used at different levels of processing by French and Spanish listeners. Spanish listeners use stress at an abstract level of processing, while French listeners are only capable of using an acoustic representation of stress which consequently impair their performance when different speakers produced the nonsense words. The French listeners difficulties in using stress has been replicated in several subsequent studies (Dupoux, Peperkamp \& Sebastián-Gallés, 2001; Dupoux, Peperkamp \& SebastianGalles, 2010; Peperkamp, Vendelin \& Dupoux, 2010) even in French listeners learning of Spanish (Dupoux, Sebastián-Gallés, Navarrete \& Peperkamp, 2008), and the terms "stress deafness" have been widely employed to qualify these difficulties.

In this study, we tried to better understand the difficulties encountered by French listeners with stress, and why such difficulties have been reported. An alternative explanation for the difficulty of French listeners in the Dupoux et al. study could be related to the use of 
stimuli that do not respect the rules of stress placement in French. In the Dupoux et al. study, $1^{\text {st }} / 2^{\text {nd }}$ stressed syllables ('bopelo/bo'pelo) and $2^{\text {nd }} / 3^{\text {rd }}$ stressed syllables (bo'pelo/bope'lo) were used, but in French, a word cannot receive primary stress at any non-final position. We thus re-examined the French listeners ability to use stress during word processing, and tested them on legal and illegal stress patterns in French. More specifically, three stress patterns on bisyllabic French words were tested: (1) the legal stress pattern in French, namely words that were unstressed compared to words that bore primary stress on their last syllable: jury/ju'ry (the 'unstressed/2nd stressed syllable' pattern), (2) an illegal stress location pattern, namely words that bore primary stress on their first syllable compared to words that bore primary stress on their second syllable: 'jury/ju'ry (the ' $1^{\text {st }}$ stressed syllable/2 $2^{\text {nd }}$ stressed syllable' pattern) and (3) an illegal stress pattern that involves an unstressed word, namely words that were unstressed compared to words that bore primary stress on their first syllable : jury/jury (the 'unstressed $/ 1^{\text {st }}$ stressed syllable' pattern). We predicted that if the difficulties reported in the Dupoux et al. study are due to the use of stress patterns that do not respect the rules of stress placement in French, difficulties should be observed for the ' 1 st $s$ stressed syllable/ $2^{\text {nd }}$ stressed syllable' pattern ('jury/ju'ry), and that these difficulties would extend to the 'unstressed/1 ${ }^{\text {st }}$ stressed syllable' pattern (jury/ 'jury) which is also not encountered in French. In particular for these two illegal stress patterns in French, French listeners should perform worse on a stress difference ('jury vs. ju'ry; jury vs. 'jury) than on a phoneme difference (e.g. 'jury vs. 'juron). By comparison, good performance is expected for the 'unstressed/2nd $s$ stressed syllable' pattern (jury /ju'ry) because this is precisely $T H E$ stress pattern that respects the rules of stress placement in French. In particular, for this last stress pattern, French listeners should use stress difference (jury vs. ju'ry) as they use phonemic difference (e.g. ju'ry vs. ju'ron) to discriminate between two words and they should perform equally well on a stress and a phoneme difference. 
As in Dupoux et al.'s study, we used an ABX task in which participants heard three items produced by three different speakers and had to indicate whether X was identical to A or B. Within the three stress patterns tested, the stimuli A and B varied either in stress (e.g. ju'ry, jury, ju'ry), or in one phoneme (e.g. ju'ry, ju'ron, ju'ry') so that the relative contribution of phonemic and stress information could be examined for each stress pattern. Finally, similar to Dupoux et al. (1997)'s study, a last condition in which A and B differed both in stress and in one phoneme was tested within each stress pattern. This allowed us to test whether French listeners could benefit from stress information when phonemic information alone is sufficient to differentiate the two members of a minimal pair (e.g., ju'ry, juron, ju'ry). In particular, a boost in the performance when stress and phonemic information is cumulated could be observed for the 'unstressed $/ 2^{\text {nd }}$ stressed syllable' pattern, because this precisely for this stress pattern that a good performance in perceiving the difference in stress is expected. 


\section{Method}

Participants: Twenty-four native speakers of French (18 women) between 18 and 26 years old $($ mean $=22,5)$ participated in the experiment. All were students from Aix-Marseille University and all reported having no neurological or hearing impairment. Each participant gave informed consent prior to experimentation and was remunerated for their time with 10 Euros.

Materials: Four pairs of bisyllabic French words, four phonemes in length, differing either in the initial (momie /momi/ "mummy" vs. vomi /vomi/ "vomit", musée /myze/ “museum” vs. rusé /ьуzе/ "clever”) or in the last phoneme (jury/зуві/ "jury” vs. juron/зувว̃/

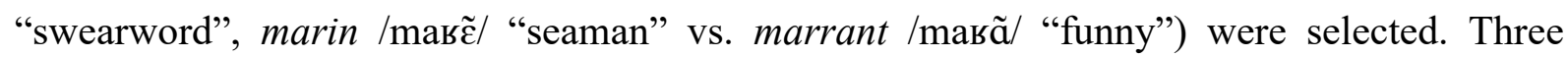
French speakers (two women, one man) produced the 8 target words (in capital letters in the following example) within carrier sentences in which the target word bore stress on the last syllable or was unstressed depending on its position within the utterance (e.g., [On m'avait parlé] [d'un JURY exi'geant] [qu'il était difficile] [de satisfaire] vs. [On m'avait parlé] [d'un exigeant JU'RY] [qu'il était difficile] [de satisfaire] "I was told about a highly demanding jury that it was difficult to satisfy"). The same carrier sentences as for the unstressed condition were used to obtain 8 target words that bore stress on the first syllable (e.g. [On m'avait parlé] [d'un 'JURY exi'geant] [qu'il était difficile] [de satisfaire]). Because words that bore primary stress on the first syllable are not found in French, speakers were asked to produce stress on the first syllable of the target word by making the target syllable prominent. To avoid coarticulation effects due to contextualized-speech, each word was extracted from its carrier sentences, and the three speakers heard their own productions of the 8 target words 
in their stressed (first stressed syllable and second stressed syllable) and unstressed versions in isolation, and were instructed to reproduce the different versions. The sentences and the 8 target words presented in isolation were recorded at a sampling rate of $44100 \mathrm{~Hz}$. Acoustic analyses using Praat software (Boersma \& Weenink, 2015) were then conducted to ensure that the repeated words were produced with the expected stress patterns. Pre-boundary lengthening and f0 rises, the two main correlates of primary stress in French, were measured (see Table 1). Figure 1 illustrates the words jury/зуьi/ "jury" produced by our male speaker in its unstressed version, with a primary stress on its last syllable and with a primary stress on its first syllable. Statistical analyses performed on the 8 target words produced by the three speakers show that for the unstressed words, the duration and the f0 rise associated with the first syllables were not different from those of the second syllables [syllable duration: $t(23)=$ $0.09, p>.20$; f0 rise: $t(23)=0.65 ; p>.20]$. By contrast, for the words that bore stress on the $1^{\text {st }}$ syllable, the first syllables were longer and associated with a stronger f0 rise than the $2^{\text {nd }}$ syllables [syllable duration: $t(23)=7.20, p<.0001$; f0 rise: $t(23)=13.78 ; p<.0001$ ]. For the words that bore stress on the $2^{\text {nd }}$ syllable, the $2^{\text {nd }}$ syllables were longer and associated with a stronger $\mathrm{f} 0$ rise than the $1^{\text {st }}$ syllables [syllable duration: $t(23)=7.81, p<.0001$; f0 rise: $t(23)=$ 33.32; $p<.0001]$. The root-mean-squared (rms) amplitude levels for all the target words were equated at a level of $70 \mathrm{~dB}$ SPL.

$<$ Table 1 about here $>$

$<$ Figure 1 about here $>$

From the recorded words, 576 trials were constructed. Each trial consisted of three stimuli: A, B and X, with the first two spoken by the two females and the third by the male. Within each stress pattern (' $1{ }^{\text {st }}$ stressed syllable $/ 2^{\text {nd }}$ stressed syllable', 'unstressed $/ 2^{\text {nd }}$ stressed syllable', 'unstressed $/ 1^{\text {st }}$ stressed syllable'), A and B varied either in stress, in one phoneme or 
both in stress and in one phoneme, leading thus to 9 experimental conditions. The four pairs of words were used in each experimental condition. For each pair of words and within each experimental condition, 16 combinations resulted from the crossing between stress (2 versions), segmental contents ( 2 words), response type (A or B) and voice (two females). Each of the experimental conditions is illustrated in Table 2 with the "jury-juron" (/зувi//зувว̃/) pair of words.

$<$ Table 2 about here $>$

Procedure: Participants were tested in a sound attenuated booth, and stimuli were presented over headphones at a comfortable sound level (60dBA). Each experimental trial presented the three stimuli (A, B and X) separated by an interval of 500ms. Participants were told that the first two stimuli were different, and that the third one was identical to the first or to the second. They were required to press a button on their left or on their right to indicate whether X was identical to A or to B respectively. Each participant heard the 576 trials, which were presented randomly, and a short break was given to the participants after 288 trials. The order of presentation of trials was different for each participant. An inter-trial interval of 1000 ms elapsed between the participant's response and the beginning of the next trial. Reaction times (RTs) were measured from the onset of the target word (stimulus X). The participants began the experiment with a block of 12 practice trials. 


\section{Results}

Accuracy rates and mean RTs are shown in Table 3.

$<$ Table 3 about here $>$

Accuracy rate analyses: We analyzed accuracy data $(1=$ correct responses, $0=$ incorrect responses) using a mixed-effects regression model (lme4 package in R-studio statistics Version 0.99 .903 ) with a logistic linking function. The model included mismatch (phoneme mismatch, stress mismatch, phoneme and stress mismatch) and stress pattern $\left(1^{\text {st }}\right.$ stressed

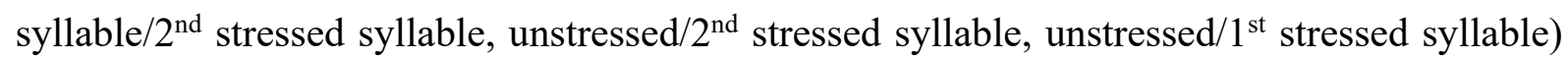
as fixed effects. The model included participants and items as random intercepts only (random slopes by participants and by items were not included because they did not allow the model to converge). Global effects were obtained using the afex::mixed function. The model revealed a significant main effect of mismatch $\left(X^{=}=181.64, \mathrm{p}<.0001\right)$. The effect of stress pattern was not significant $\left(X^{2}=1.02, \mathrm{p}>.20\right)$. Crucially the interaction between mismatch and stress pattern was significant $\left(X^{2}=22.49, \mathrm{p}<.001\right)$. To further analyse the mismatch $\mathrm{x}$ stress pattern interaction, the $3 \times 3$ factor design was converted into a $1 \times 9$ factor design using the same model structure. Multiple comparisons (Tukey test, $\mathrm{p}<.05$ ) were obtained with the glht function from the multcomp package (Bretz, Hothorn \& Westfall, 2011) with p-values adjusted by the single step method. For the ' $1{ }^{\text {st }}$ stressed syllable $/ 2^{\text {nd }}$ stressed syllable' pattern (e.g., 'jury/ju'ry), the model revealed more correct responses in the phoneme mismatch condition compared to the stress mismatch condition $(\mathrm{z}=6.53, \mathrm{p}<.001)$. There were also more correct responses in the phoneme and stress mismatch condition compared to the stress 
mismatch condition $(\mathrm{z}=8.89, \mathrm{p}<.001)$. However, the difference between the phoneme and stress mismatch condition compared to the phoneme mismatch condition failed to reach significance $(\mathrm{z}=2.82, \mathrm{p}=.11)$. For the 'unstressed $/ 2^{\text {nd }}$ stressed syllable' pattern (e.g., jury/ju'ry), no significant difference was found between the phoneme mismatch condition and the stress mismatch condition $(\mathrm{z}=1.00, \mathrm{p}>.20)$ while participants gave more correct responses in the phoneme and stress mismatch condition compared to both the phoneme mismatch condition $(\mathrm{z}=6.83, \mathrm{p}<.001)$ and the stress mismatch condition $(\mathrm{z}=7.68, \mathrm{p}<$ .001). Similarly, for the 'unstressed/1 ${ }^{\text {st }}$ stressed syllable' pattern (e.g., jury/'jury), no significant difference was found between the phoneme mismatch and the stress mismatch conditions $(\mathrm{z}=1.90, \mathrm{p}>.20)$ while participants gave more correct responses in the phoneme and stress mismatch condition compared to both the phoneme mismatch $(\mathrm{z}=3.99, \mathrm{p}<.01)$ and the stress mismatch condition $(\mathrm{z}=5.76, \mathrm{p}<.001)$.

RTs analyses: These analyses were performed only on correct responses. One absurd data $(\mathrm{RTs}=13028 \mathrm{~ms})$ was excluded. A linear mixed-effects regression model was used on the log-transformed RTs (fixed effects: mismatch and stress pattern; random intercepts: participants and items; no random slopes because they did not allow the model to converge). The model revealed both a significant main effect of mismatch $\left(X^{2}=64.20, \mathrm{p}<.0001\right)$, and a significant main effect of stress pattern $\left(X^{=}=120.76, \mathrm{p}<.0001\right)$. Crucially, the interaction between mismatch and stress pattern was significant $\left(X^{2}=30.70, p<.0001\right)$. To further analyse the mismatch $\mathrm{x}$ stress pattern interaction, the $3 \times 3$ factor design was converted into a $1 \mathrm{x} 9$ factor design using the same model structure. Multiple comparisons (Tukey test, $\mathrm{p}<.05$ ) were obtained with the glht function from the multcomp package (Bretz et al., 2011) with pvalues adjusted by the single step method. For the ' $1^{\text {st }}$ stressed syllable/2 $2^{\text {nd }}$ stressed syllable' pattern (e.g., 'jury / ju'ry), participants responded faster in the phoneme mismatch condition 
than in the stress mismatch condition $(\mathrm{z}=6.65, \mathrm{p}<.0001)$. They were also faster in the phoneme and stress mismatch condition compared to the stress mismatch condition $(\mathrm{z}=8.02$, $\mathrm{p}<.0001)$. No significant difference was found between the phoneme and stress mismatch and the phoneme mismatch conditions $(\mathrm{z}=1.36, \mathrm{p}=0.17)$. For the 'unstressed syllable $/ 2^{\text {nd }}$ stressed syllable' pattern (e.g., jury/ju'ry), no significant difference was found between the phoneme mismatch and the stress mismatch conditions $(\mathrm{z}=1.48, \mathrm{p}=.14)$. Participants were faster in the phoneme and stress mismatch condition compared to both the phoneme mismatch $(\mathrm{z}=2.05, \mathrm{p}<.05)$ and the stress mismatch conditions $(\mathrm{z}=3.55, \mathrm{p}<.001)$. Similarly, for the 'unstressed/1 st stressed syllable' pattern (e.g., jury/'jury), no significant difference was found between the phoneme mismatch condition compared to the stress mismatch condition $(\mathrm{z}=-$ 0.452, $\mathrm{p}>.20$ ). Participants were faster in the phoneme and stress mismatch condition than both in the stress mismatch condition $(\mathrm{z}=2.28, \mathrm{p}<.05)$ and in the phoneme mismatch condition $(\mathrm{z}=2.75, \mathrm{p}<.01)$ 


\section{Discussion}

Our study examined the contribution of stress and segmental information in the discrimination of French words. In light of the results of Dupoux et al. (1997)'s study, we hypothesized that French listeners would experience difficulties in using stress during word discrimination, when they are faced with stress patterns that do not respect the rules of stress placement in French. In accordance with our prediction, French listeners performed worse on stress differences ('jury vs. ju'ry) than on phoneme differences ('jury vs. 'juron) when the stress pattern involved two words stressed either in their first or second syllable. Hence, we have replicated Dupoux et al.'s results for stress patterns that are prohibited in French. In accordance with our prediction, our results indicated that French listeners perform equally well on stress (ju'ry vs. jury) and phoneme differences (ju'ry, ju'ron), for the unique legal stress pattern in French, namely for words that were unstressed or bore stress on their last syllable. Unexpected however was the observation that French listeners also performed equally well on stress ('jury vs. jury) and phoneme differences ('jury vs. 'juron), when the stress pattern involved two words that were either unstressed or stressed on their first syllable, and so for a stress pattern which is not found in French.

What our results reveal is that French listeners experience difficulties with stress when they have to discriminate between two words that differ in stress location. No difficulty is observable when French listeners have to discriminate between an unstressed word and a stressed word, and this, regardless of the position of the stress (first/second syllable) in the stressed words. Such findings are particularly important since they suggest that French listeners are fully capable of discriminating an unstressed word from its stressed counterpart even if the stress pattern is not legal in their language. French listeners thus use the presence 
versus absence of stress information as they use phonemic information to discriminate between words. An alternative explanation to our findings could be that the comparison between stressed and unstressed words is a simpler task than the comparison between words that differ in stress location. Although more studies are required to definitively discard this possibility, we believe that this is rather unlikely mainly because this is not in these particular stress mismatch conditions that the better performances were observed.

Crucially, our study shows that the difficulties of French listeners with stress mainly reside in locating stress within words. Nonetheless, it seems important to underline that French listeners are not deaf to differences in stress location. As it was already the case in Dupoux et al. (1997)'s study, French listeners showed performance above the chance level in the $1^{\text {st }}$ stressed syllable/2 $2^{\text {nd }}$ stressed syllable pattern, thus corroborating the claim that French listeners indeed use stress information. Nonetheless, for this stress pattern, no benefit in the discrimination of words was observed when the difference between words is carried out by stress difference in addition to phonemic difference. Hence, for stress patterns which are difficult to process, French listeners appear to ignore stress information when word discrimination can be made on phonemic information. In contrast, when French listeners have no difficulty in processing stress information - when stress patterns included an unstressed words - differences between words on both phonemic and stress information are the easiest to process, thus suggesting that French listeners under some circumstances use stress information together with phonemic information to discriminate between words.

The present results converge in showing that French listeners are able to categorize a word as stressed or unstressed but experience difficulties to establish categories based on stress location. Similarly to what it has been observed in Italian listeners (Sulpizio \& 
McQueen, 2012), an explanation to our findings could be in terms of abstract prosodic knowledge in French listeners. According to Sulpizio and McQueen (2012), Italian listeners have abstracted the knowledge that in their language, trisyllabic words usually have penultimate stress, and they use this knowledge during word recognition. Because in the French language, primary stress falls on the last syllable of the melodic group, French listeners inevitably encounter unstressed words more frequently than stressed words in everyday communication (Jun \& Fougeron, 2000), and they have likely abstracted the knowledge that French words are more often unstressed. As a consequence, their performance is optimized when they encounter these default unstressed words, and they experience no difficulty in discriminating between two words differing in their accentual pattern provided that the stress pattern is made-up of an unstressed word.

To conclude, the present research tempers the idea of so-called "stress deafness" in French. French listeners appear to use stress information in the same way as they use phonemic information to discriminate between words, provided that the stress pattern is made up of unstressed words. The difficulties that French listeners can experience mainly reside in the location of stress within a word. Further research is now required to examine how prosodic information is integrated into lexical representations, and whether the unstressed version of words is stored by default in the French mental lexicon. 


\section{Footnotes}

1. We use the term "stress" as a synonym of "accent" to refer to the phonetic/perceptual prominence of a syllable which affects words or units larger than the words.

2. We use the IPA stress mark "'” before the stressed syllable to indicate stress. For more clarity, the stressed syllable is also in bold.

3. While the obligatory stress (i.e. called primary stress) can never occur on the first syllable of words in French, an optional secondary stress can affect it. This secondary stress is rather unfrequent on bisyllabic words (Michelas \& D'Imperio, 2012). It is more likely to occur with words that contain more than two syllables, when the speaking rate is slow and in case of specific speech style such as conference and journalistic style (Jun \& Fougeron, 2000; Welby, 2006). For instance, the word diffamation "defamation" tends to be produced with a secondary stress on its first syllable and a primary stress on its final syllable at a slow speech rate (diffama'tion). Importantly, this secondary stress does not have the same acoustic properties as the primary stress. It is cued by an initial f0 rise realized on the syllable which is not accompanied by syllabic lengthening, unlike for primary stress (Jun \& Fougeron, 2000; Welby, 2006). 


\section{Acknowledgments}

This work was supported by the Labex Brain and Language Research Institute (ANR-11LABX-0036) and has benefited from support from the French National Agency of Research (ANR), under the project title "Investments of the Future" A*MIDEX (ANR-11-IDEX-000102). We thank Zeynep Özyurt for her help in running the experiment. 


\section{References}

Banel, M. H., and Bacri, N. (1994). On metrical patterns and lexical parsing in French, Speech Communication, 15, 115-126. doi:10.1016/0167-6393(94)90046-9.

Boersma, P., and Weenink, D. (2015). “Praat. Doing phonetics by computer” (Version 5.4.01, 2015), Computer program: www.praat.org (Last viewed April 30, 2015).

Bretz, F., Hothorn, T., \& Westfall, P. H. (2011). Multiple comparisons using R. Boca Raton: CRC Press.

Christophe, A., Peperkamp, S., Pallier, C., Block, E., \& Mehler, J. (2004). Phonological phrase boundaries constrain lexical access I. Adult data, Journal of Memory and Language, 51, 523-547. doi:10.1016/j.jml.2004.07.001.

Cutler, A., \& Otake,T. (1999). Pitch accent in spoken word recognition in Japanese. Journal of the Acoustical Society of America, 105,1977-1988. Doi : 10.1121/1.426724.

Cutler, A., \& Van Donselaar, W. (2001). Voornaam is not (really) a homophone: Lexical prosody and lexical access in Dutch. Language and speech, 44, 171-195. doi: 10.1177/00238309010440020301.

Dixon, P. (2008). Models of accuracy in repeated-measures designs. Journal of Memory and Language, 59, 447-456. doi:10.1016/j.jml.2007.11.004.

Dupoux, E., Pallier, C., Sebastian, N., \& Mehler, J. (1997). A destressing "deafness" in French?, Journal of Memory and Language, 36, 406-421. doi:10.1006/jmla.1996.2500.

Dupoux, E., Peperkamp, S., \& Sebastián-Gallés, N. (2001). A robust method to study stress "deafness", Journal of Acoustical Society of America, 110, 1606-1618. doi: $10.1121 / 1.1380437$.

Dupoux, E., Peperkamp, S., \& Sebastián-Gallés, N. (2010). Limits on bilingualism revisited: Stress 'deafness' in simultaneous French-Spanish bilinguals, Cognition, 114, 266-275. 
doi:10.1016/j.cognition.2009.10.001.

Dupoux, E., Sebastián-Gallés, N., Navarrete, E., \& Peperkamp, S. (2008). Persistent stress 'deafness': The case of French learners of Spanish. Cognition, 106(2), 682-706.

Jaeger, T. F. (2008). Categorical data analysis: away from ANOVAs (transformation or not) and towards logit mixed models. Journal of Memory and Language, 59, 434-446.

doi: $10.1016 /$ j.jml.2007.11.007.

Jun, S. A., \& Fougeron, C. (2000). A phonological model of French intonation. In A. Botinis (Eds.), Intonation: Analysis, Modelling and Technology (209-242). Boston, MA: Kluwer Academic Publishers. doi: 10.1007/978-94-011-4317-2_10.

Lee, C.-Y. (2000). Lexical tone in spoken word recognition: A view from Mandarin Chinese. Unpublished doctoral dissertation, Brown University. Providence, RI.

McQueen, J. M., Norris, D., \& Cutler, A. (1994). Competition in spoken word recognition: Spotting words in other words. Journal of Experimental Psychology: Learning, Memory, and Cognition, 20, 621. doi: 10.1037/0278-7393.20.3.621.

Michelas, A., D’Imperio, M. (2012). When syntax meets prosody: Tonal and duration variability in French Accentual Phrases. Journal of Phonetics, 40(6), 816-829. doi:10.1016/j.wocn.2012/08.004.

Peperkamp, S., Vendelin, I., \& Dupoux, E. (2010). Perception of predictable stress: A cross linguistic investigation, Journal of Phonetics, 38, 422-430. doi:10.1016/j.wocn.2010.04.001.

Rietveld, A. C. M. (1980). Word boundaries in the French language, Language and Speech 23, 289-296. doi: 10.1177/002383098002300306.

Spinelli, E., Welby, P., \& Schaegis, A. L. (2007). Fine-grained access to targets and competitors in phonemically identical spoken sequences: the case of French elision, Language and Cognitive Processes, 22, 828-859. doi: 10.1080/01690960601076472. 
Spinelli, E., Grimault, N., Meunier, F., \& Welby, P. (2010). An intonational cue to word segmentation in phonemically identical sequences, Attention, Perception, \& Psychophysics, 72, 775-787. doi:10.3758/APP.72.3.775.

Soto-Faraco, S., Sebastián-Gallés, N., \& Cutler, A. (2001). Segmental and suprasegmental mismatch in lexical access. Journal of Memory and Language, 45, 412-432. doi:10.1006/jmla.2000.2783.

Sulpizio, S., \& McQueen, J. M. (2012). Italians use abstract knowledge about lexical stress during spoken-word recognition. Journal of Memory and Language, 66, 177-193. doi:10.1016/j.jml.2011.08.001.

Welby, P. (2006). French intonational structure: Evidence from tonal alignment. Journal of Phonetics, 34, 343-371. doi:10.1016/j.wocn.2005.09.001. 
Table 1. Acoustic properties of target words in their unstressed and stressed versions $\left(1^{\text {st }}\right.$ and $2^{\text {nd }}$ stressed syllable) for the three speakers (averaged on the eight target words).

\begin{tabular}{|c|c|c|c|c|c|c|c|c|c|}
\hline \multirow{2}{*}{$\begin{array}{l}\text { Stress } \\
\text { pattern }\end{array}$} & \multirow[t]{2}{*}{ Speaker } & \multicolumn{4}{|c|}{$1^{\text {st }}$ syllable } & \multicolumn{4}{|c|}{$2^{\text {nd }}$ syllable } \\
\hline & & $\begin{array}{l}\text { Syllable } \\
\text { duration } \\
(\mathrm{ms})\end{array}$ & $\begin{array}{c}\mathrm{f} 0 \\
\text { minima* } \\
(\mathrm{Hz})\end{array}$ & $\begin{array}{c}\mathrm{f0} \\
\text { maxima* } \\
(\mathrm{Hz})\end{array}$ & $\begin{array}{l}\mathrm{f} 0 \\
\text { rise } \\
(\%)\end{array}$ & $\begin{array}{c}\text { Syllable } \\
\text { duration } \\
\text { (ms) }\end{array}$ & $\begin{array}{c}\mathrm{f0} \\
\text { minima* } \\
(\mathrm{Hz})\end{array}$ & $\begin{array}{c}\mathrm{f0} \\
\text { maxima* } \\
(\mathrm{Hz})\end{array}$ & $\begin{array}{l}\mathrm{f0} \\
\text { rise } \\
(\%)\end{array}$ \\
\hline \multirow{4}{*}{$\begin{array}{l}\text { Unstressed } \\
\text { (e.g., jury) }\end{array}$} & Male & 125 & 106 & 101 & -4 & 126 & 100 & 94 & -6 \\
\hline & Female 1 & 129 & 200 & 194 & -3 & 129 & 194 & 188 & -2 \\
\hline & Female 2 & 143 & 228 & 218 & -4 & 141 & 215 & 200 & -7 \\
\hline & Mean & 132 & 178 & 171 & -4 & 132 & 170 & 161 & -5 \\
\hline \multirow{4}{*}{$\begin{array}{l}1^{\text {st }} \text { stressed } \\
\text { syllable } \\
\text { (e.g., 'jury) }\end{array}$} & Male & 257 & 123 & 161 & 31 & 182 & 97 & 90 & -7 \\
\hline & Female 1 & 241 & 218 & 318 & 47 & 180 & 192 & 179 & -7 \\
\hline & Female 2 & 305 & 226 & 332 & 48 & 184 & 218 & 207 & -5 \\
\hline & Mean & 268 & 189 & 270 & 42 & 182 & 169 & 159 & -6 \\
\hline \multirow{4}{*}{$\begin{array}{l}2^{\text {nd }} \text { stressed } \\
\text { syllable } \\
\text { (e.g., ju'ry) }\end{array}$} & Male & 184 & 102 & 93 & -8 & 267 & 93 & 260 & 180 \\
\hline & Female 1 & 184 & 192 & 171 & -10 & 254 & 170 & 441 & 161 \\
\hline & Female 2 & 203 & 213 & 193 & -9 & 290 & 192 & 560 & 193 \\
\hline & Mean & 190 & 169 & 152 & -9 & 270 & 152 & 420 & 178 \\
\hline
\end{tabular}

* f0 minima and f0 maxima labels are only appropriate for stressed words, for unstressed words they correspond to the onset and offset of the syllable. 
Table 2. Illustration of the experimental conditions with the jury-juron /зивi/-/зивг̃/ pair of words. ${ }^{\mathrm{F} 1}$ and ${ }^{\mathrm{F} 2}$ indicate the two female voices and ${ }^{\mathrm{M}}$ the male voice.

\begin{tabular}{|c|c|c|c|c|c|c|c|c|c|c|c|c|}
\hline & \multicolumn{3}{|c|}{ Stress mismatch } & \multirow{2}{*}{$\begin{array}{l}\text { Correct } \\
\text { response }\end{array}$} & \multicolumn{3}{|c|}{ Phoneme mismatch } & \multirow{2}{*}{$\begin{array}{l}\text { Correct } \\
\text { response }\end{array}$} & \multicolumn{3}{|c|}{ Phoneme \& stress mismatch } & \multirow{2}{*}{$\begin{array}{l}\text { Correct } \\
\text { response }\end{array}$} \\
\hline & $\mathbf{A}$ & B & $\mathbf{X}$ & & $\mathbf{A}$ & B & $\mathbf{X}$ & & $\mathbf{A}$ & B & $\mathbf{X}$ & \\
\hline \multirow{16}{*}{$\begin{array}{l}\text { ' } 1^{\text {st }} \\
\text { stressed } \\
\text { syllable/2nd } \\
\text { stressed } \\
\text { syllable' } \\
\text { pattern }\end{array}$} & F1'jury & F2 ju'ry & M 'jury & $\mathrm{A}$ & F1 'jury & F2'juron & $\mathrm{M}_{\text {'jury }}$ & $\mathrm{A}$ & F1 'jury & F2 ju'ron & $\mathrm{M}_{\text {'jury }}$ & $\mathrm{A}$ \\
\hline & F2 'jury & F1 ju'ry & ${ }^{M}$ 'jury & A & F2 'jury & F1 'juron & ${ }^{M}$ 'jury & A & F2 'jury & ${ }^{\mathrm{F}} 1$ ju'ron & ${ }^{M}$ 'jury & A \\
\hline & F1 ju'ry & F2 'jury & $\mathrm{M}$ 'jury & $\mathrm{B}$ & F1 juron & F2 'jury & $\mathrm{M}_{\text {'jury }}$ & $\mathrm{B}$ & ${ }^{\mathrm{F} 1}$ ju'ron & F2 'jury & $\mathrm{M}$ 'jury & B \\
\hline & F2 ju'ry & F1 'jury & $\mathrm{M}$ 'jury & $\mathrm{B}$ & F2 'juron & F1 'jury & M 'jury & $\mathrm{B}$ & F2 ju'ron & F1 'jury & $\mathrm{M}$ 'jury & $\mathrm{B}$ \\
\hline & F1 ju'ry & F2 'jury & ${ }^{M}$ ju'ry & A & F1 'juron & F2 'jury & M 'juron & A & ${ }^{\mathrm{F} 1}$ ju'ry & F2 'juron & ${ }^{\mathrm{M}}$ ju'ry & A \\
\hline & F2 ju'ry & F1 'jury & ${ }^{M}$ ju'ry & $\mathrm{A}$ & F2 'juron & F1 'jury & M 'juron & $\mathrm{A}$ & F2 ju'ry & F1 'juron & ${ }^{\mathrm{M}}$ ju'ry & A \\
\hline & F1 'jury & F2 ju'ry & $\mathrm{M}_{\text {ju'ry }}$ & B & F1 'jury & F2 'juron & M 'juron & B & F1 'juron & F2 ju'ry & $\mathrm{M}_{\text {ju'ry }}$ & B \\
\hline & F2 'jury & ${ }^{F 1}$ ju'ry & ${ }^{M}$ ju'ry & B & F2 'jury & F1 'juron & $M_{\text {'juron }}$ & B & F2 'juron & F1 ju'ry & ${ }^{M}$ ju'ry & B \\
\hline & F1'juron & ${ }^{F} 2$ ju'ron & $\mathrm{M}_{\text {'juron }}$ & A & ${ }^{\mathrm{F} 1}$ ju'ry & ${ }^{\mathrm{F} 2}$ ju'ron & ${ }^{\mathrm{M}}$ ju'ry & A & F1 'juron & F2 ju'ry & ${ }^{M}$ 'juron & A \\
\hline & F2 'juron & ${ }^{\mathrm{F} 1}$ ju'ron & $M_{\text {'juron }}$ & A & F2 ju'ry & ${ }^{\mathrm{F} 1}$ ju'ron & ${ }^{\mathrm{M}}$ ju'ry & A & F2 'juron & ${ }^{\mathrm{F} 1}$ ju'ry & $M_{\text {'juron }}$ & A \\
\hline & ${ }^{\mathrm{F} 1}$ ju'ron & F2 'juron & $\mathrm{M}_{\text {'juron }}$ & B & ${ }^{\mathrm{F}} 1$ ju'ron & F2 ju'ry & ${ }^{\mathrm{M}}$ ju'ry & B & ${ }^{\mathrm{F} 1}$ ju'ry & F2 'juron & $\mathrm{M}_{\text {'juron }}$ & B \\
\hline & ${ }^{F 2}$ ju'ron & F1'juron & $\mathrm{M}_{\text {'juron }}$ & B & ${ }^{\mathrm{F} 2}$ ju'ron & ${ }^{\mathrm{F} 1}$ ju'ry & ${ }^{\mathrm{M}}$ ju'ry & B & ${ }^{\mathrm{F} 2}$ ju'ry & F1 'juron & ${ }^{M}$ 'juron & B \\
\hline & ${ }^{\mathrm{F} 1}$ ju'ron & F2 'juron & ${ }^{M}$ ju'ron & A & ${ }^{\mathrm{F} 1}$ ju'ron & F2 ju'ry & $\mathrm{M}_{\text {ju'ron }}$ & A & $\mathrm{F} 1$ ju'ron & F2 'jury & ${ }^{M}$ ju'ron & A \\
\hline & ${ }^{F} 2$ ju'ron & F1 'juron & ${ }^{M}$ ju'ron & A & F2 ju'ron & ${ }^{\mathrm{F} 1}$ ju'ry & ${ }^{M}$ ju'ron & A & ${ }^{F} 2$ ju'ron & F1 'jury & ${ }^{\mathrm{M}}$ ju'ron & A \\
\hline & F1 'juron & F2 ju'ron & ${ }^{\mathrm{M}}$ ju'ron & B & F1 ju'ry & ${ }^{\mathrm{F} 2}$ ju'ron & ${ }^{\mathrm{M}}$ ju'ron & B & F1 'jury & F2 ju'ron & ${ }^{\mathrm{M}}$ ju'ron & B \\
\hline & F2 'juron & ${ }^{\mathrm{F} 1}$ ju'ron & ${ }^{\mathrm{M}}$ ju'ron & B & F2 ju'ry & ${ }^{\mathrm{F} 1}$ ju'ron & ${ }^{\mathrm{M}}$ ju'ron & B & F2 'jury & ${ }^{\mathrm{F} 1}$ ju'ron & ${ }^{\mathrm{M}}$ ju'ron & B \\
\hline \multirow{16}{*}{$\begin{array}{l}\text { 'unstressed } \\
/ 2^{\text {nd }} \\
\text { stressed } \\
\text { syllable' } \\
\text { pattern }\end{array}$} & ${ }^{\mathrm{F} 1}$ jury & F2 jury & $\mathrm{M}_{\text {jury }}$ & $\mathrm{A}$ & ${ }^{\mathrm{F} 1}$ jury & F2 juron & $\mathrm{M}_{\text {jury }}$ & $\mathrm{A}$ & $\mathrm{F}^{\mathrm{F}}$ jury & F2 ju'ron & $\mathrm{M}_{\text {jury }}$ & $\mathrm{A}$ \\
\hline & F2 iury & ${ }^{\mathrm{F} 1}$ jury & ${ }^{M}$ jury & A & F2 jury & ${ }^{F} 1$ juron & ${ }^{M}$ jury & A & F2 jury & ${ }^{\mathrm{F} 1}$ ju'ron & ${ }^{M}$ jury & A \\
\hline & ${ }^{\mathrm{F} 1}$ ju'ry & F2 jury & ${ }^{M}$ jury & B & ${ }^{\mathrm{F} 1}$ juron & F2 jury & ${ }^{M}$ jury & B & ${ }^{\mathrm{F} 1}$ ju'ron & F2 jury & ${ }^{\mathrm{M}}$ jury & B \\
\hline & F2 ju'ry & ${ }^{\mathrm{F}} 1$ jury & ${ }^{M}$ jury & B & F2 juron & ${ }^{\mathrm{F} 1}$ jury & $\mathrm{M}_{\text {jury }}$ & B & ${ }^{F} 2$ ju'ron & F1 jury & ${ }^{M}$ jury & B \\
\hline & F1 ju'ry & F2 jury & ${ }^{\mathrm{M}}$ ju'ry & A & $\mathrm{F} 1$ juron & F2 jury & $\mathrm{M}$ juron & A & ${ }^{\mathrm{F} 1}$ ju'ry & F2 juron & M ju'ry & A \\
\hline & F2 ju'ry & ${ }^{\mathrm{F}} 1$ jury & ${ }^{M}$ ju'ry & A & F2 juron & ${ }^{\mathrm{F} 1}$ jury & $\mathrm{M}_{\text {juron }}$ & $\mathrm{A}$ & F2 ju'ry & $\mathrm{F} 1$ juron & ${ }^{M}$ ju'ry & A \\
\hline & F1 jury & F2 ju'ry & ${ }^{\mathrm{M}}$ ju'ry & B & F1 jury & F2 juron & $\mathrm{M}$ juron & B & $\mathrm{F} 1$ juron & F2 ju'ry & ${ }^{M}$ ju'ry & B \\
\hline & F2 jury & ${ }^{F 1}$ ju'ry & $\mathrm{M}_{\text {ju'ry }}$ & B & F2 jury & $\mathrm{F} 1$ juron & $\mathrm{M}$ juron & B & F2 juron & ${ }^{\mathrm{F} 1}$ ju'ry & $\mathrm{M}_{\text {ju'ry }}$ & B \\
\hline & $\mathrm{F} 1$ juron & F2 ju'ron & $\mathrm{M}$ juron & A & F1 ju'ry & F2 ju'ron & $\mathrm{M}_{\text {ju'ry }}$ & A & $\mathrm{F} 1$ juron & F2 ju'ry & $\mathrm{M}$ juron & A \\
\hline & F2 juron & ${ }^{\mathrm{F} 1}$ ju'ron & $\mathrm{M}$ juron & A & F2 ju'ry & ${ }^{\mathrm{F} 1}$ ju'ron & ${ }^{\mathrm{M}}$ ju'ry & A & F2 juron & ${ }^{\mathrm{F} 1}$ ju'ry & ${ }^{M}$ juron & A \\
\hline & ${ }^{\mathrm{F} 1}$ ju'ron & F2 juron & $\mathrm{M}$ juron & B & ${ }^{\mathrm{F} 1}$ ju'ron & ${ }^{\mathrm{F} 2}$ ju'ry & ${ }^{M}$ iu'ry & B & ${ }^{\mathrm{F} 1}$ ju'ry & $\mathrm{F} 2$ juron & $\mathrm{M}$ juron & B \\
\hline & ${ }^{\mathrm{F} 2}$ ju'ron & $\mathrm{F} 1$ juron & ${ }^{M}$ juron & B & ${ }^{\mathrm{F} 2}$ ju'ron & ${ }^{\text {F1 ju'ry }}$ & ${ }^{\mathrm{M}}$ ju'ry & B & F2 ju'ry & ${ }^{F} 1$ juron & ${ }^{M}$ juron & B \\
\hline & ${ }^{\mathrm{F}} 1$ ju'ron & F2 juron & ${ }^{\mathrm{M}}$ ju'ron & A & ${ }^{\mathrm{F} 1}$ ju'ron & F2 ju'ry & ${ }^{M}$ ju'ron & A & ${ }^{\mathrm{F} 1}$ ju'ron & F2 jury & ${ }^{\mathrm{M}}$ ju'ron & A \\
\hline & ${ }^{F 2}$ ju'ron & ${ }^{\mathrm{F} 1}$ juron & ${ }^{M}$ ju'ron & A & ${ }^{F 2}$ ju'ron & ${ }^{\mathrm{F} 1}$ ju'ry & ${ }^{\mathrm{M}}$ ju'ron & A & ${ }^{F}$ ju'ron & ${ }^{\mathrm{F}} 1$ jury & ${ }^{M}$ ju'ron & A \\
\hline & $\mathrm{F} 1$ juron & ${ }^{F 2}$ ju'ron & ${ }^{M}$ ju'ron & B & ${ }^{\mathrm{F} 1}$ ju'ry & ${ }^{\mathrm{F} 2}$ ju'ron & ${ }^{M}$ ju'ron & B & $\mathrm{F} 1$ jury & ${ }^{F 2}$ ju'ron & ${ }^{M}$ ju'ron & B \\
\hline & $\mathrm{F} 2$ juron & ${ }^{\mathrm{F} 1}$ ju'ron & ${ }^{\mathrm{M}}$ ju'ron & B & F2 ju'ry & ${ }^{\mathrm{F} 1}$ ju'ron & ${ }^{\mathrm{M}}$ ju'ron & $\mathrm{B}$ & F2 jury & ${ }^{\mathrm{F} 1}$ ju'ron & ${ }^{\mathrm{M}}$ ju'ron & $\mathrm{B}$ \\
\hline \multirow{16}{*}{$\begin{array}{l}\text { 'unstressed } \\
/ 1^{\text {st }} \text { stressed } \\
\text { syllable' } \\
\text { pattern }\end{array}$} & F1'jury & F2 jury & $\mathrm{M}$ 'jury & $\mathrm{A}$ & F1'jury & F2'juron & $\mathrm{M}_{\text {'jury }}$ & $\mathrm{A}$ & F1'jury & $\mathrm{F} 2$ juron & $\mathrm{M}$ 'jury & $\bar{A}$ \\
\hline & F2 'jury & F1 jury & M 'jury & A & F2 'jury & F1 'juron & $M_{\text {'jury }}$ & A & F2 'jury & $\mathrm{F} 1$ juron & M 'jury & A \\
\hline & F1 jury & F2' 'jury & M 'jury & B & F1 'juron & F2 'jury & M 'jury & B & ${ }^{\mathrm{F}}$ juron & F2 'jury & M 'jury & B \\
\hline & $\mathrm{F} 2$ jury & F1 'jury & M 'jury & B & F2 '̈juron & F1 'jury & M 'jury & B & F2 juron & F1 'jury & M 'jury & B \\
\hline & $\mathrm{F} 1$ jury & F2 'jury & $\mathrm{M}$ jury & A & F1 'juron & F2 'jury & $M$ 'juron & A & F1 jury & F2 'juron & $\mathrm{M}$ jury & A \\
\hline & F2 jury & F1 'jury & $\mathrm{M}$ jury & A & F2 'juron & F1 'jury & $\mathrm{M}_{\text {'juron }}$ & A & F2 jury & F1 'juron & $\mathrm{M}$ jury & A \\
\hline & F1 'jury & F2 jury & $\mathrm{M}_{\text {jury }}$ & B & F1'jury & F2 'juron & $M_{\text {'juron }}$ & B & F1 'juron & F2 jury & $\mathrm{M}_{\text {jury }}$ & B \\
\hline & F2 'jury & F1 jury & $\mathrm{M}_{\text {jury }}$ & B & F2 'jury & F1 'juron & M 'juron & B & F2 'juron & $\mathrm{F} 1$ jury & $\mathrm{M}_{\text {jury }}$ & B \\
\hline & F1'juron & $\mathrm{F} 2$ juron & ${ }^{M}$ 'juron & A & F1 jury & F2 juron & M jury & A & F1 'juron & $\mathrm{F}^{2}$ jury & ${ }^{M}$ 'juron & A \\
\hline & F2 'juron & ${ }^{\mathrm{F} 1}$ juron & $\mathrm{M}_{\text {'juron }}$ & A & F2 jury & $\mathrm{F} 1$ juron & $\mathrm{M}_{\text {jury }}$ & A & F2 'juron & ${ }^{\mathrm{F}} 1$ jury & $M_{\text {'juron }}$ & A \\
\hline & $\mathrm{F} 1$ juron & F2 'juron & M 'juron & B & $\mathrm{F} 1$ juron & F2 jury & $\mathrm{M}$ jury & B & F1 jury & F2 'juron & $\mathrm{M}_{\text {'juron }}$ & B \\
\hline & F2 juron & F1 'juron & $\mathrm{M}_{\text {'juron }}$ & B & F2 juron & ${ }^{\mathrm{F} 1}$ jury & $\mathrm{M}_{\text {jury }}$ & B & F2 jury & F1 'juron & ${ }^{M}$ 'juron & B \\
\hline & $\mathrm{F} 1$ juron & F2 'juron & $\mathrm{M}$ juron & A & F1 juron & ${ }^{F 2}$ jury & $\mathrm{M}$ juron & A & ${ }^{\mathrm{F} 1}$ juron & F2 'jury & ${ }^{\mathrm{M}}$ juron & A \\
\hline & F2 juron & F1'juron & $\mathrm{M}_{\text {juron }}$ & $\mathrm{A}$ & F2 juron & F1 jury & $\mathrm{M}_{\text {juron }}$ & A & F2 juron & F1 'jury & $\mathrm{M}_{\text {juron }}$ & A \\
\hline & F1 'juron & F2 juron & $\mathrm{M}_{\text {juron }}$ & B & F1 jury & F2 juron & $\mathrm{M}_{\text {juron }}$ & B & F1 'jury & F2 juron & $\mathrm{M}_{\text {juron }}$ & B \\
\hline & F2 'juron & ${ }^{\mathrm{F} 1}$ juron & ${ }^{M}$ juron & $\mathrm{B}$ & ${ }^{\mathrm{F} 2}$ jury & ${ }^{\mathrm{F} 1}$ juron & ${ }^{\mathrm{M}}$ juron & $\mathrm{B}$ & F2 'jury & ${ }^{\mathrm{F} 1}$ juron & ${ }^{\mathrm{M}}$ juron & $\mathrm{B}$ \\
\hline
\end{tabular}


Table 3. Accuracy rates and mean RTs (in ms) for the three stress patterns and the three mismatch conditions. Standard deviations are given in parenthesis.

\begin{tabular}{lccc}
\hline & Phoneme mismatch & Stress mismatch & $\begin{array}{c}\text { Phoneme and stress } \\
\text { mismatch }\end{array}$ \\
\hline $\begin{array}{l}\mathbf{1}^{\text {st }} \text { stressed syllable/2 }^{\text {nd }} \\
\text { stressed syllable } \\
\text { \% of correct responses }\end{array}$ & & & \\
RTs & 93 & 85 & 95 \\
\hline $\begin{array}{l}\text { Unstressed/2nd } \text { stressed } \\
\text { syllable }\end{array}$ & $1090(256)$ & $1203(311)$ & $1064(240)$ \\
$\begin{array}{l}\% \text { of correct responses } \\
\text { RTs }\end{array}$ & & & \\
\hline $\begin{array}{l}\text { Unstressed/1st stressed } \\
\text { syllable } \\
\text { \% of correct responses }\end{array}$ & 89 & 88 & 96 \\
RTs & $1056(243)$ & $1071(271)$ & $1027(249)$ \\
\hline
\end{tabular}




\section{Figure}
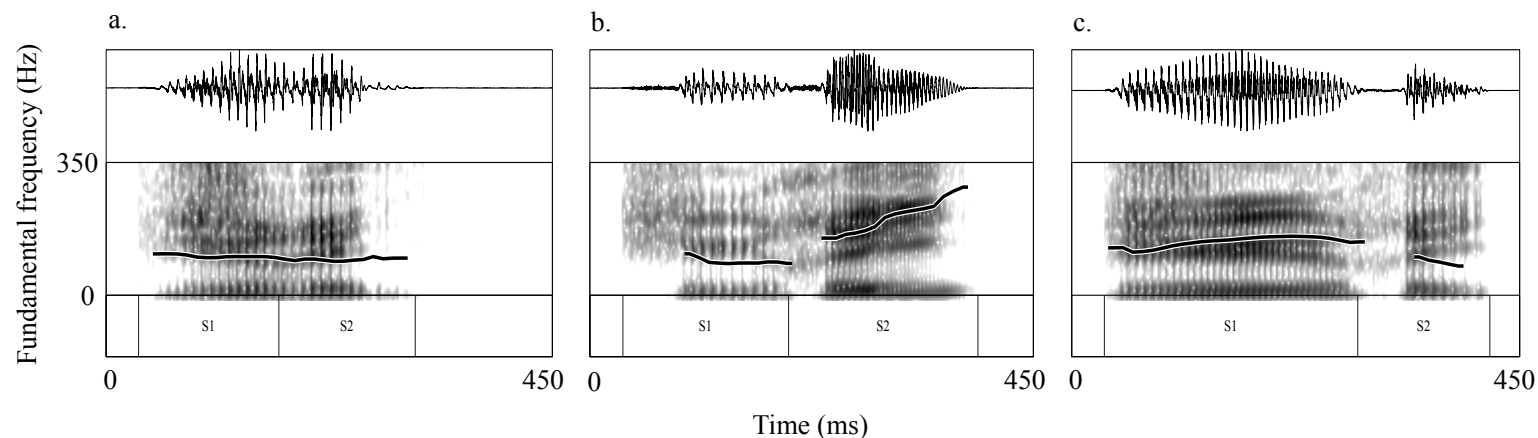

Figure 1. Phonemic and prosodic profile for the target word jury produced by the male voice in its unstressed version (a), with primary stress on its second syllable (b) and with primary stress on its first syllable (c). 